\title{
Dose Exposure and Diagnostic Capability of Split Bolus Computed Tomography Urography (CTU): Comparison with Single Bolus Technique
}

\section{Clarissa Valle ${ }^{1,2 *}$, Pietro Andrea Bonaffini ${ }^{1}$, Maurizio Balbi ${ }^{1,2}$, Francesca Invernizzi ${ }^{2}$, Noemi Liggeri ${ }^{1,3}$, Carlo Maria Ludovico Mondellini $^{1,3}$, Annalisa Pappini ${ }^{2}$ and Sandro Sironi ${ }^{1,3}$}

${ }^{1}$ Post-Graduate School of Diagnostic Radiology, University of Milano-Bicocca, Italy

${ }^{2}$ Desio Hospital, Department of Diagnostic Radiology, University of Milano-Bicocca, Italy

${ }^{3}$ ASST Papa Giovanni XXIII, Department of Diagnostic Radiology, University of Milano-Bicocca, Italy

*Corresponding Author: Clarissa Valle, Post-Graduate School of Diagnostic Radiology, University of Milano-Bicocca, Italy.
Received: September 27, 2021

Published: December 08, 2021

(c) All rights are reserved by Clarissa Valle., et al.

\begin{abstract}
Objectives: To compare CT urography (CTU) split bolus with standard protocol in terms of urinary tract opacification, parenchymal and vascular enhancement, and radiation dose exposure. To assess split bolus CTU diagnostic capability.

Methods: Forty-eight patients (18-83 years) were retrospectively analysed: 24 (study group) performed a split-bolus CTU (combined nephrographic-excretory phase), 24 (control group) a single bolus protocol. On combined and portal venous phases, quantitative analysis of intraluminal opacification and parenchymal-vascular enhancement (HU) was achieved by placing regions of interest (ROI) in urinary tract, liver, spleen, kidneys, abdominal aorta and inferior vena cava. The corresponding mean HU values were compared between 2 groups. Qualitative analysis of urinary intraluminal opacification was performed by two radiologists using a fourpoint scale; inter-observer agreement was calculated. Radiation dose was calculated as Dose Length Product (DLP) and Computed Tomography Dose Index Volume (CTDIvol). The diagnostic capability was evaluated using a 2-point scale, using histology, imaging follow-up and endoscopy as reference standard.

Results: The split-bolus protocol demonstrated lower mean urinary attenuation compared to the control group but no differences in quality of urinary tract opacification or in parenchymal-vascular enhancement. Mean DLP was lower $(p=0.045)$ in the study group (reduction of 37\%). Split-bolus protocol answered the clinical question in 22/24 cases.

Conclusions: With a comparable urinary tract opacification, parenchymal organs and vessels enhancement, split-bolus CTU results in a proper accuracy with a dose reduction of $37 \%$, as compared to single-bolus protocols.
\end{abstract}

Keywords: Computed Tomography; Split Bolus; Radiation Dose; Kidneys; Urinary Tract

\section{Abbreviations}

CT: Computed Tomography; CTU: Computed Tomography Urography; ACR: American College Radiology; HU: Hounsfield Units; CM: Contrast Medium; BT: Bolus Tracking; ROI: Region of Interest; DLP: Dose Length Product; CTDI vol: Computed Tomography Dose Index Volume; SD: Standard Deviation; CI: Confidence Interval; MDCT: Multidetector Computed Tomography; IVC: Inferior Vena
Cava; MRI: Magnetic Resonance Imaging; MPR: Multiplanar Reconstruction; MIP: Maximum Intensity Projection

\section{Introduction}

CT urography (CTU) is the primary imaging modality for the simultaneous evaluation of kidneys and urinary tract [1]. It furnishes a complete assessment of abdomen and pelvis through a direct vi- 
sualization of organs, vessels, and adjacent structures. Common indications are urolithiasis, urinary obstruction, haematuria workup, urothelial neoplasms, traumatic/iatrogenic ureteral injuries, and urinary tract infections [2]. Additional indications are congenital or post-surgical urinary tract anomalies and any scenario where a detailed evaluation of urinary tract is needed [3].

In these scenarios, considering the potential multiple CT studies that patients may undergo during their disease, radiation dose delivery should be kept as low as possible while preserving an overall diagnostic quality for proper image evaluation [4-6]. A CTU study typically comprises three phases: unenhanced (haemorrhage and stones detection), nephrographic (parenchymal lesions assessment) and excretory (collecting system, ureters, and bladder evaluation). To reduce the number of phases is the easiest tool to obtain dose exposure reduction [7]. Split-bolus techniques can lead to a radiation dose exposure reduction by allowing a combined acquisition of two different contrast-enhanced dynamic phases in one. To the best of our knowledge, split-bolus has been applied in several urological settings, with the original aim to improve urinary tract visualization. Other fields were also explored, with excellent results and significant radiation dose reduction, both in adult and paediatric patients: liver and pancreatic lesions detection and characterization, renal donors' evaluation, acute abdominal pain and pulmonary embolism [8-11]. As per the latest guidelines from the American College of Radiology (ACR), split bolus CTU is mentioned as potential tool for the evaluation of indeterminate renal masses, haematuria, acute onset flank pain with suspicion of stone ad acute pyelonephritis, even employing dual-energy machines. However, split bolus CTU benefits are still unclear, therefore not allowing to consider it as the reference standard in uroradiology [12].

The purpose of our study was to analyse the urinary tract opacification qualitatively and quantitatively, quantitatively evaluate abdominal organ enhancement and report the corresponding radiation dose exposure in split-bolus CTU studies, as compared to single-bolus protocol. The diagnostic capability of split-bolus protocol was also evaluated using histology, follow-up, and endoscopy as reference standard.

\section{Materials and Methods}

Study population

We retrospectively analysed 48 patients who underwent CTU between January and December 2015. The main clinical indica- tions for CTU were oncologic disease, urolithiasis, haematuria, hydronephrosis and trauma with suspected urinary injuries.

The patients were divided in 2 groups, according to the scanning protocol. The study group consisted of 24 patients (range 1883 years; 7 females) scanned with a split-bolus protocol (Figure 1). The control group included 24 patients (range 22-83 years; 9 females) who underwent a standard single-bolus technique. The inclusion criteria were the following: a) age at the time of CT of 18 or older; b) no radical cystectomy; c) no artefacts (i.e., motion or metal devices) impairing image evaluation. A final number of excluded patients has not been annotated. Informed consent was obtained before CT acquisition from all individual participants included in the study. Anonymity and confidentiality of the collected data was insured.

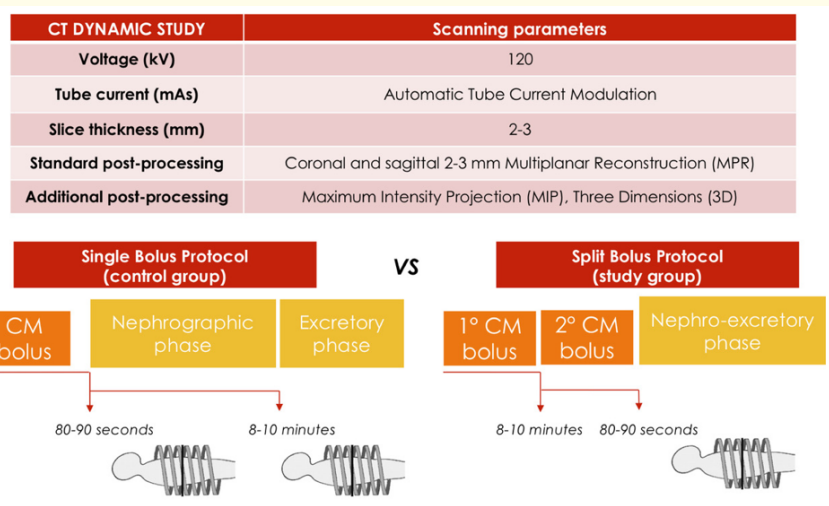

Figure 1: Split Bolus CTU protocol main parameters. Axial images along with multiplanar reconstruction (MPR) are generally used for exam evaluation. Maximum-Intensity-Projection (MIP) and $3 \mathrm{D}$ reconstructions are performed in selected cases, to better visualize the main arterial vessels (arterial phase), whole urinary tract anatomy and renal masses relation with collecting system (nephro-urographic phase). MIP are generally performed with a slice thickness of $10 \mathrm{~mm}$ and $7 \mathrm{~mm}$ interval. CTU: computed tomography urography; BT: bolus tracking.

Scanning protocols: single and split bolus CTU

All CTU were performed on a 64-row scanner (Aquilion, Toshiba Medical), with automated tube current-modulation, to adjust the tube current in real time for image noise maintenance at the 
optimal level [13] and a standard $120 \mathrm{kV}$ set up. Patients were positioned prone. Additional supine scanning was not performed in any case. Neither intravenous diuretic drugs nor external abdominal compression were used, as per standard departmental protocol.

A baseline unenhanced scan (diaphragm to trochanter minor) is generally performed during first examinations. It is mainly used for stones detection and to furnish lesions/collections baseline HU values. For standard CTU, iodinated contrast medium (CM; Omnipaque 350, GE Healthcare) was then administered in an antecubital vein at a standard dose of $1.5 \mathrm{ml} / \mathrm{kg}$ and a flow rate of 3-3.5 ml/ sec, followed by a 30-50 mL saline flush at the same flow rate. An additional injection of $100 \mathrm{~mL}$ saline flush (flow rate $1 \mathrm{~mL} / \mathrm{sec}$ ) is performed after the completion of the first CM-saline flush administration, to obtain a proper urine excretion and bladder filling in the excretory phase. Due to the retrospective nature of the study, minor variations in saline flush could not be completely addressed but were considered unlikely affecting the overall urinary tract distension and opacification. After the intravenous administration of a single CM bolus, the standard CTU study protocol is based on the acquisition of portal venous and excretory phases of the volume of interest (upper and whole abdomen, respectively) for most of the pathologies affecting the urinary tract (i.e., stones or suspected infections). The nephrographic phase is performed after 70-100 seconds (average 90 seconds) or 35 seconds using the bolus-tracking (BT) technique (Sure Start) while the excretory phase after 8-10 minutes.

In the split-bolus technique, the total amount of $\mathrm{CM}$ is fractionated in two consecutive boluses, with a standard infusion rate of 3.0-3.5 mL/sec: about $40 \%$ of the total amount is administered at baseline and the remaining 60\% after 8-10 minutes. Approximately 80-90 seconds after the second bolus, a single combined nephro-urographic phase is acquired. The concomitant saline flush administered is equivalent to the standard CTU protocol, in terms of both quantity and infusion rate.

An arterial phase has been additionally acquired in both the study and the control group for renal masses characterization, clear cell carcinoma and urothelial tumors (staging or follow-up), as well as in one traumatized patient (study group). After CM injection, the arterial phase is performed with a time delay of 25-35 seconds or 13 seconds using BT. To this purpose, a single region of interest (ROI) is placed within the aortic lumen using a 120-150 HU threshold. A total of 16/24 patients in the control group and $11 / 24$ patients in the study group required an additional arterial phase acquisition.

\section{Images and data analysis}

Two radiologists independently performed images analysis: a consultant (reader 1) and a resident (reader 2), with 10- and 2-years' experience in abdominal CT, respectively. The quantitative analysis was performed by manually placing circular ROI within the opacified lumen of the urinary tract, avoiding calcifications or areas of eventual urothelial thickening, both in the combined nephro-urographic (study group) and excretory phases (control group). ROI's size measurements (including ranges) were not performed but the largest area of the lumen was always covered. Mean HU values for each segment were recorded and compared between the groups.

For ROI placement, six specific anatomic sections were identified: left and right renal pelvis; upper, middle, and lower portions of left and right ureters; bladder. The ureters portions were identified as follows [14]: the upper portion extends from the ureteropelvic junction to the upper border of the sacrum; the middle portion continues from the upper to lower borders of the sacrum; the distal portion continues from the lower border of the sacrum to the ureterovesical junction.

Then, the readers independently performed a qualitative analysis of urinary tract opacification (pyelocaliceal system, ureters, bladder) in both groups, by using a 4-point scale: 0 none, 1 poor, 2 diagnostic and 3 excellent. For split-bolus diagnostic capability ( 0 no answer given, 1 question satisfied), the final diagnosis of the most experienced reader was considered. To assess diagnostic capability in answering the underlying clinical question further imaging studies, follow up, endoscopy and/or histology were used as standard reference.

Vascular and parenchymal enhancement were also measured, respectively on portal venous phases in the control group and on combined nephro-excretory phases in the study group. Vessels contrast enhancement was achieved by placing circular ROI in the lumen of infrarenal IVC and infrarenal abdominal aorta (approximately same level), avoiding any intraluminal filling defect, mural 
thrombosis or atherosclerotic changes. Parenchymal enhancement was analysed by placing ROI on liver, kidneys and spleen (avoiding vessels), as follows: 3 in liver segments II, III and IV (main portal vein bifurcation level); 3 in the upper, middle and lower poles of each kidney; 1 in splenic parenchyma (hilum level). Attenuation values (HU) recorded from ROI placed on liver and kidneys were then averaged, obtaining a single measurement for each organ.

For each CT examination, radiation dose exposure was annotated in terms of DLP ( $\left.\mathrm{mGy}^{*} \mathrm{~cm}\right)$ and CTDI vol (mGy), as automatically calculated by the CT scan. Data provided covered the total acquisition volume, therefore the entire radiation dose derived from the total sum of the acquired phases was considered.

\section{Statistical analysis}

Statistical analysis was performed using SPSS software for Windows (version 17.0; SPSS Inc.) and MedCalc for Windows (version 12.7.0.0; MedCalc Software). Age, sex and number of phases acquired were reported in terms of average \pm standard deviation (SD) and median values for each group. The Student's t test was used to evaluate differences between the study and control group in terms of patients' mean age, while the Chi-square test was used to evaluate differences in terms of sex. HU, DLP e CTDI of both groups were reported as mean values, SD and median. The Mann-Whitney U test was used to evaluate differences between the study group and the control group in terms of mean attenuation values calculated in urinary tract, vessels and parenchymal organs. Using the same test, we also compared the radiation dose exposure and image quality scores between the two groups. A p $<0.05$ was considered statistically significant. For split-bolus CTU studies the interobserver agreement of image quality scores was determined by Cohen's kappa with 95\% confidence intervals (CI): $\mathrm{k}$ values < 0 indicate poor agreement, 0-0.20 slight, 0.21-0.40 fair, 0.41-0.60 moderate, 0.61-0.80 substantial e 0.81-1.00 almost perfect, as described by Landis e Koch [15].

\section{Results and Discussion}

No significant differences were observed in terms of age or sex in both groups. As expected, the number of phases acquired (average \pm SD; median) was lower in the study group than in the control group, respectively $2.38 \pm 0.71 ; 2.50$ and $3.79 \pm 0.93 ; 4.00$.

The quantitative analysis deriving from ROI placement in the urinary tract demonstrated overall higher HU values in the stan- dard CTU protocol than in the split-bolus. As reported in table 1, we also found a progressive partial reduction of HU values from renal pelvis down to the bladder. Except for the bladder, that demonstrated the lower quantitative values, these differences were always statistically significant $(\mathrm{p}<0.05)$. No statistically significant differences regarding vascular, renal, hepatic, and splenic enhancement were found by quantitative analysis (Table $1 \mathrm{~b}$ ).

\begin{tabular}{|c|c|c|c|}
\hline \multirow[t]{2}{*}{ Anatomic site } & \multicolumn{3}{|c|}{ Quantitative analysis (HU) } \\
\hline & Study group & Control group & $\begin{array}{c}\text { p-value (p } \\
<0.05)\end{array}$ \\
\hline \multirow[t]{2}{*}{ Left renal pelvis } & $908.7 \pm 494.7$ & $1326.2 \pm 637.0$ & \multirow[t]{2}{*}{$0.043^{*}$} \\
\hline & 968.6 & 1221.6 & \\
\hline \multirow{2}{*}{$\begin{array}{l}\text { Right renal } \\
\text { pelvis }\end{array}$} & $877.1 \pm 492.1$ & $1252.7 \pm 544.6$ & \multirow[t]{2}{*}{$0.037^{*}$} \\
\hline & 910.0 & 1121.4 & \\
\hline \multirow[t]{2}{*}{ Left ureters } & $810.0 \pm 531.7$ & $1113.8 \pm 581.5$ & \multirow[t]{2}{*}{$0.044^{*}$} \\
\hline & 733.7 & 891.6 & \\
\hline \multirow[t]{2}{*}{ Right ureters } & $655.3 \pm 444.0$ & $1126.8 \pm 555.4$ & \multirow[t]{2}{*}{$0.002 *$} \\
\hline & 663.5 & 1027.2 & \\
\hline Bladder & $604.9 \pm 381.0$ & $939.4 \pm 675.2$ & 0.080 \\
\hline
\end{tabular}

Table 1a

\begin{tabular}{|c|c|c|c|}
\hline \multirow{2}{*}{$\begin{array}{l}\text { Anatomic } \\
\text { site }\end{array}$} & \multicolumn{3}{|c|}{ Quantitative analysis (HU) } \\
\hline & Study group & Control group & $\begin{array}{c}p \text {-value (p } \\
<0.05 \text { ) }\end{array}$ \\
\hline \multirow[t]{2}{*}{ Liver } & $107.3 \pm 19.54$ & $108 \pm 19.56$ & \multirow[t]{2}{*}{0.526} \\
\hline & 105.5 & 105 & \\
\hline \multirow[t]{2}{*}{ Spleen } & $112 \pm 17.39$ & $108.3 \pm 18.78$ & \multirow[t]{2}{*}{0.3182} \\
\hline & 110 & 101.5 & \\
\hline \multirow[t]{2}{*}{ Left Kidney } & $184.8 \pm 24.86$ & $182.5 \pm 26.97$ & \multirow[t]{2}{*}{0.9252} \\
\hline & 186.5 & 187 & \\
\hline \multirow{2}{*}{$\begin{array}{l}\text { Right Kid- } \\
\text { ney }\end{array}$} & $184.4 \pm 25.8$ & $179.6 \pm 22.94$ & \multirow[t]{2}{*}{0.5337} \\
\hline & 186.5 & 180 & \\
\hline \multirow[t]{2}{*}{ Aorta } & $161 \pm 26.52$ & $150.7 \pm 22.14$ & \multirow[t]{2}{*}{0.1052} \\
\hline & 155.5 & 147.5 & \\
\hline \multirow{2}{*}{$\begin{array}{c}\text { Inferior } \\
\text { vena cava }\end{array}$} & $131.2 \pm 18.51$ & $123.2 \pm 18.76$ & \multirow[t]{2}{*}{0.1422} \\
\hline & 127 & 119.5 & \\
\hline
\end{tabular}

Table 1b 


\begin{tabular}{|c|c|c|c|c|c|c|}
\hline \multirow[t]{2}{*}{ Anatomic site } & \multirow[t]{2}{*}{ CTU protocol } & \multicolumn{5}{|c|}{ Qualitative analysis } \\
\hline & & Reader 1 (R1) & p-value R1 & Reader 2 (R2) & p-value R2 & k Cohen R1-R2 (95\%CI) \\
\hline \multirow[t]{2}{*}{ Left pelvis } & Split-bolus & $2.5 \pm 0.6$ & \multirow[t]{2}{*}{0.088} & $2.8 \pm 0.5$ & \multirow[t]{2}{*}{0.344} & $0,114(-0,119$ to 0,348$)$ \\
\hline & Traditional & $2.8 \pm 0.5$ & & $2.9 \pm 0.4$ & & $0,543(-0,00895$ to 1,000$)$ \\
\hline \multirow[t]{2}{*}{ Left upper ureter } & Split-bolus & $2.6 \pm 0.9$ & \multirow[t]{2}{*}{0.741} & $2.9 \pm 0.3$ & \multirow[t]{2}{*}{0.912} & $0,404(0,119$ to 0,689$)$ \\
\hline & Traditional & $2.6 \pm 0.9$ & & $2.8 \pm 0.7$ & & $0,415(-0,0529$ to 0,883$)$ \\
\hline \multirow[t]{2}{*}{ Left middle ureter } & Split-bolus & $2.6 \pm 1.0$ & \multirow[t]{2}{*}{0.633} & $2.7 \pm 0.8$ & \multirow[t]{2}{*}{0.909} & $0,298(-0,242$ to 0,838$)$ \\
\hline & Traditional & $2.8 \pm 0.7$ & & $2.7 \pm 0.8$ & & $0,452(-0,121$ to 1,000$)$ \\
\hline \multirow[t]{2}{*}{ Left lower ureter } & Split-bolus & $2.2 \pm 1.1$ & \multirow[t]{2}{*}{0.866} & $2.4 \pm 0.9$ & \multirow[t]{2}{*}{0.960} & $0,706(0,430$ to 0,983$)$ \\
\hline & Traditional & $2.2 \pm 1.1$ & & $2.4 \pm 1.0$ & & $0,390(0,0773$ to 0,703$)$ \\
\hline \multirow[t]{2}{*}{ Right pelvis } & Split-bolus & $2.7 \pm 0.6$ & \multirow[t]{2}{*}{0.746} & $2.9 \pm 0.3$ & \multirow[t]{2}{*}{0.613} & $0,375(0,0457$ to 0,704$)$ \\
\hline & Traditional & $2.8 \pm 0.5$ & & $2.8 \pm 0.5$ & & $0,538(0,0687$ to 1,000$)$ \\
\hline \multirow[t]{2}{*}{ Right upper ureter } & Split-bolus & $2.7 \pm 0.8$ & \multirow[t]{2}{*}{0.399} & $2.7 \pm 0.6$ & \multirow[t]{2}{*}{0.955} & $0,462(0,190$ to 0,733$)$ \\
\hline & Traditional & $2.5 \pm 1.1$ & & $2.5 \pm 1.1$ & & $0,660(0,299$ to 1,000$)$ \\
\hline \multirow[t]{2}{*}{ Right middle ureter } & Split-bolus & $2.6 \pm 0.8$ & \multirow[t]{2}{*}{0.509} & $2.3 \pm 1.1$ & \multirow[t]{2}{*}{0.321} & $0,381(0,141$ to 0,621$)$ \\
\hline & Traditional & $2.3 \pm 1.2$ & & $2.5 \pm 1.1$ & & $0,549(0,225$ to 0,874$)$ \\
\hline \multirow[t]{2}{*}{ Right lower ureter } & Split-bolus & $1.9 \pm 1.1$ & \multirow[t]{2}{*}{0.913} & $2.0 \pm 1.1$ & \multirow[t]{2}{*}{0.233} & $0,521(0,264$ to 0,779$)$ \\
\hline & Traditional & $1.9 \pm 1.2$ & & $2.3 \pm 1.1$ & & $0,487(0,168$ to 0,807$)$ \\
\hline \multirow[t]{2}{*}{ Bladder } & Split-bolus & $1.6 \pm 0.8$ & \multirow[t]{2}{*}{0.482} & $1.5 \pm 0.7$ & \multirow[t]{2}{*}{0.123} & $0,462(0,200$ to 0,723$)$ \\
\hline & Traditional & $1.8 \pm 0.8$ & & $1.8 \pm 0.6$ & & $0,667(0,460$ to 0,873$)$ \\
\hline
\end{tabular}

Table 1c

Table 1: Summary of quantitative (a, b) and qualitative analysis (c) in the two groups (study and control). Quantitative analysis of urinary tract, performed in the combined (study group) and delayed phases (control group) (a). Quantitative analysis of vascular and parenchymal structures, performed in the combined (study group) and venous phases (control group) (b). Qualitative analysis of urinary tract, performed by 2 readers (R1 and R2) and interobserver agreement (c). HU: Hounsfield Unit. CTU: computed tomography urography.

Data from the qualitative analysis of the urinary tract are reported in Table 1c. Despite a not homogenous inter-observer agreement, the overall opacification of the whole urinary tract was generally rated either diagnostic or almost excellent between the two CT groups, except for the bladder and partially for the lower portion of the right ureter.

Concerning radiation dose exposure, DLP and CTDIvol were lower in the study group as compared to the control group. A statistically significant difference was found only for DLP (1869.29 \pm 1103.48 vs $3002.19 \pm 2399.76 \mathrm{mGy} \mathrm{cm}$ ). CTDIvol demonstrated a trend towards reduction (57.29 \pm 39.93 vs $97.21 \pm 85.91 \mathrm{mGy})$, even if not statistically significant. Accordingly, the split-bolus allowed a reduction of radiation dose exposure of $37 \%$.
Follow-up, laboratory/clinical data, or final histopathological results were available for $19 / 24$ cases (study group) (Table 2 ). The mean follow-up was of 9.5 months (range 0.5-24 months). There were 10 true positives ( 6 benign, 4 malignant), 6 true negative ( 3 oncological follow-up, 2 suspected urolithiasis, 1 suspected tumor), 2 false negatives ( 2 flat urothelial carcinomas) and 1 false positive (suspected tumor recurrence). This given, sensitivity, specificity and accuracy of split bolus protocols resulted $0.83,0.86$ and 0.84 respectively. The remaining 5 patients had no further examinations performed at our Institution and were lost at follow up (1 suspected prostate cancer, 3 urolithiasis and 1 hydronephrosis for probable pyeloureteral junction syndrome. 
67

\begin{tabular}{|c|c|c|c|c|c|c|c|c|c|}
\hline Age & Sex & Clinical indication & Main CT findings & Final diagnosis & Diagnostic proof & TP & FP & TN & FN \\
\hline 70 & M & Haematuria & Negative & $\begin{array}{l}\text { Flat urothelial } \\
\text { carcinoma }\end{array}$ & Histology (cystoscopy) & & & & $\mathrm{x}$ \\
\hline 66 & M & Bladder cancer staging & $\begin{array}{c}\text { Diverticula. No wall } \\
\text { thickening/ } \\
\text { enhancement }\end{array}$ & $\begin{array}{l}\text { Flat urothelial } \\
\text { carcinoma }\end{array}$ & Histology (surgery) & & & & $\mathrm{x}$ \\
\hline 69 & $\mathrm{~F}$ & $\begin{array}{l}\text { Endometrial carci- } \\
\text { noma follow up; pelvic } \\
\text { nodes and vaginal } \\
\text { vault metastasis. Left } \\
\text { double J catheter }\end{array}$ & $\begin{array}{l}\text { Left pelvis and ure- } \\
\text { teral inflammatory } \\
\text { changes, worsened } \\
\text { hydronephrosis }\end{array}$ & $\begin{array}{l}\text { Stent related poly- } \\
\text { uria and dysuria }\end{array}$ & Clinical follow up & $\mathrm{X}$ & & & \\
\hline 83 & M & $\begin{array}{l}\text { Suspected bladder } \\
\text { cancer }\end{array}$ & Bladder lesion & $\begin{array}{l}\text { Invasive bladder } \\
\text { cancer }\end{array}$ & Histology (surgery) & $\mathrm{X}$ & & & \\
\hline 81 & M & $\begin{array}{l}\text { Bladder cancer follow } \\
\text { up }\end{array}$ & Negative & No recurrence & $\begin{array}{l}\text { Cystoscopy and urine cytol- } \\
\text { ogy }\end{array}$ & & & $\mathrm{X}$ & \\
\hline 78 & M & $\begin{array}{l}\text { Bladder cancer follow } \\
\text { up }\end{array}$ & Negative & No recurrence & Cystoscopy & & & $\mathrm{X}$ & \\
\hline 76 & M & Haematuria & $\begin{array}{l}\text { Prostatic enlarged, } \\
\text { detrusor hypertrophy }\end{array}$ & $\begin{array}{c}\text { Benign prostatic } \\
\text { hyperplasia (BPH) }\end{array}$ & $\begin{array}{c}\text { Cystoscopy and clinical } \\
\text { evaluation }\end{array}$ & $\mathrm{X}$ & & & \\
\hline 76 & M & $\begin{array}{l}\text { Suspected left hydro- } \\
\text { nephrosis. Known } \\
\text { renal cysts }\end{array}$ & $\begin{array}{l}\text { No hydronephrosis. } \\
\text { Bilateral renal cysts }\end{array}$ & Negative & $\begin{array}{l}\text { Emergency department } \\
11 \text { months later for acute } \\
\text { abdominal pain; negative } \\
\text { ultrasound and urological } \\
\text { examination }\end{array}$ & & & $\mathrm{X}$ & \\
\hline 74 & M & $\begin{array}{l}\text { Suspected right renal } \\
\text { lesion }\end{array}$ & Right renal lesion & Right renal lesion & $\begin{array}{l}\text { Histology by surgery (onco- } \\
\text { cytoma) }\end{array}$ & $\mathrm{X}$ & & & \\
\hline 71 & M & $\begin{array}{l}\text { Bladder cancer follow } \\
\text { up }\end{array}$ & Negative & No recurrence & $\begin{array}{l}\text { Cystoscopy, ureteroscopy } \\
\text { and urine cytology }\end{array}$ & & & $\mathrm{X}$ & \\
\hline 70 & $\mathrm{~F}$ & Nephrolithiasis & $\begin{array}{c}\text { Left hydronephrosis } \\
\text { and bilateral nephro- } \\
\text { lithiasis }\end{array}$ & $\begin{array}{l}\text { Left multifocal } \\
\text { nephrolithiasis }\end{array}$ & $\begin{array}{l}\text { Ureteroscopy, retrograde } \\
\text { pyelography and double J } \\
\text { catheter }\end{array}$ & $\mathrm{X}$ & & & \\
\hline 59 & $\mathrm{~F}$ & $\begin{array}{l}\text { Left renal function } \\
\text { exclusion, left nephro- } \\
\text { lithiasis }\end{array}$ & $\begin{array}{l}\text { Atrophic left kidney, } \\
\text { reduced nephro- } \\
\text { graphic enhancement, } \\
\text { delayed urine excre- } \\
\text { tion }\end{array}$ & $\begin{array}{l}\text { Diffuse left chronic } \\
\text { pyelonephritis }\end{array}$ & Histology (surgery) & $\mathrm{X}$ & & & \\
\hline 57 & M & Haematuria & Right renal tumor & Right renal tumor & $\begin{array}{l}\text { Surgery performed in out- } \\
\text { side center. Post tumorec- } \\
\text { tomy changes at follow up } \\
\text { CT with no local recurrence } \\
\text { or metastatic disease. }\end{array}$ & $\mathrm{X}$ & & & \\
\hline
\end{tabular}




\begin{tabular}{|c|c|c|c|c|c|c|c|}
\hline 53 & M & $\begin{array}{l}\text { Haematuria in bladder } \\
\text { cancer follow up }\end{array}$ & Bladder lesion & $\begin{array}{l}\text { Urothelial bladder } \\
\text { cancer }\end{array}$ & Histology (cystoscopy) & $\mathrm{X}$ & \\
\hline 50 & $\mathrm{~F}$ & Nephrolithiasis & Left nephrolithiasis & Left nephrolithiasis & $\begin{array}{c}\text { Extracorporeal Shock Wave } \\
\text { Lithotripsy (ESWL) }\end{array}$ & $\mathrm{X}$ & \\
\hline 50 & M & $\begin{array}{l}\text { Urachal mucinous } \\
\text { adenocarcinoma } \\
\text { restaging }\end{array}$ & $\begin{array}{l}\text { Eccentric bladder } \\
\text { right posterior wall } \\
\text { thickening }\end{array}$ & $\begin{array}{c}\text { Post-surgical } \\
\text { changes in the right } \\
\text { posterior bladder } \\
\text { wall }\end{array}$ & $\begin{array}{l}\text { Cystoscopy and ureteros- } \\
\text { copy }\end{array}$ & $\mathrm{X}$ & \\
\hline 49 & M & Trauma & $\begin{array}{l}\text { Active arterial bleed- } \\
\text { ing in right inferior } \\
\text { pubic ramus fracture }\end{array}$ & $\begin{array}{c}\text { Active arterial } \\
\text { bleeding by right } \\
\text { internal iliac artery } \\
\text { branch }\end{array}$ & $\begin{array}{l}\text { Emergency embolization in } \\
\text { outside center }\end{array}$ & $\mathrm{X}$ & \\
\hline 31 & M & Haematuria & Negative & Negative & $\begin{array}{l}\text { Cystoscopy and urine cytol- } \\
\text { ogy }\end{array}$ & & $\mathrm{X}$ \\
\hline 18 & $\mathrm{~F}$ & $\begin{array}{l}\text { Suspected ureteral } \\
\text { stone }\end{array}$ & Negative & Negative & Ultrasound follow up & & $\mathrm{X}$ \\
\hline
\end{tabular}

Table 2: Diagnostic accuracy of split bolus CTU. Clinical or imaging follow-up, cystoscopy and histology were used as standard reference.

MDCT represents the main imaging technique for renal and urinary tract evaluation [16,17], but to the best of our knowledge, no standard CTU protocols have been widely accepted (12). Therefore, the need to acquire at least both the nephrographic and excretory phase is the main background for considering the split-bolus CTU technique. Split-bolus CTU protocol is technically feasible, allowing to obtain in a single volume acquisition the typical findings of the nephrographic (i.e., proper renal parenchyma enhancement, along with liver, spleen and pancreas) and excretory phases (i.e., urinary tract opacification). The high-resolution acquisitions allow performing additional reconstructions (MPR, 3D, MIP), with better visualization of both vascularity and whole urinary tract anatomy, while the collecting system is opacified during the combined nephro-urographic phase.

By employing a dual-energy CT scanner, Karlo., et al. [18] reported urinary tract complete opacification in 94\% of patients, with a diagnostic accuracy of $98 \%$ on a per-renal-unit basis and $96 \%$ on a per-patient basis, respectively (excellent inter-reader agreement). To the best of our knowledge, there are no previous reports quantitatively evaluating the urinary tract opacification in split-bolus CTU. The contrast injection fractionation may lead to a slightly higher overall CM dose as compared to that used in a traditional multiphasic study [19]. However, the reported diagnostic efficacy is comparable to the traditional protocols in terms of imaging quality, in accordance to Chow., et al. [20]. In our cohort of patients, the CM dose was kept standard to the patient's weight, as aforementioned.

In our study the overall urinary tract $\mathrm{HU}$ values resulted significantly lower in the study group, likely because the first bolus, meant for urinary tract opacification, represents $40 \%$ of the total amount of CM. The bladder demonstrated the lowest HU values and qualitative scores, but this did not affect the image quality or evaluation of potential lesions (Figure 2). The two independent readers qualitatively scored the overall opacification of the urinary tract as diagnostic/excellent in both groups, despite an inhomogeneous inter-observer agreement. This emphasizes that the splitbolus CTU can allow a proper evaluation of kidneys and ureters, as reported in other studies [21].

Split bolus CTU showed also an excellent diagnostic capability in answering the underlying clinical question (Table 2). The two cases in which the split bolus was inconclusive were mainly blad- 

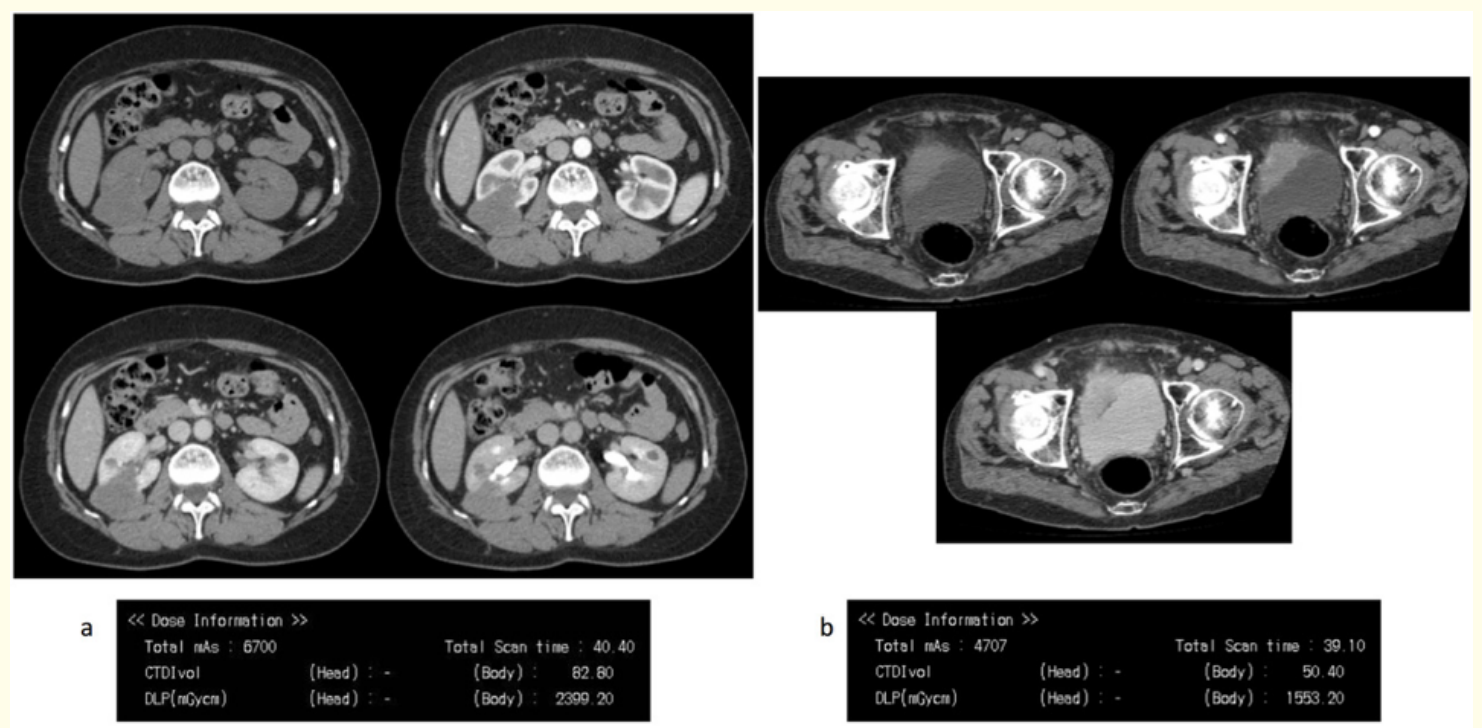

Figure 1: Comparison of radiation dose data obtained in a standard CTU study (a) and a split bolus CTU examination (b). Split bolus CTU was performed for suspected urothelial lesion of the bladder, with an additional arterial phase. Despite the reduced bladder opacification, the CTU examination properly evaluated the neoplastic lesion on the anterior and right-side wall, protruding into the lumen. The concomitant stranding of the adjacent fat is also properly appreciable. The CTDI vol and the DLP are lower in the split-bolus protocol (b), as shown.

der flat tumors, revealed after cystoscopy. To this regard, although MDCT has a sensitivity up to $80-85 \%$ in detecting bladder tumours [21], small and flat lesions may be missed [22] and cystoscopy remains the gold standard [23].

The 2 readers observed comparable mean attenuation values in the enhanced liver, spleen, aorta, IVC and kidneys between the groups. HU values in the liver, spleen and IVC were higher than those observed in three different split-bolus protocols by Lee., et al. [24] and in line with those observed by Chen., et al. in aorta and liver [25]. Given the good enhancement, both readers were able to properly identify and characterize incidental findings in both groups (i.e., simple cystic lesions or aortic atheromatous disease). This was not stated in terms of statistical significance but reported by the readers who denied differences in the interpretative assessment of such findings between standard portal-venous and combined nephro-urographic phases. The benign nature of parenchymal lesions was confirmed by clinical data and follow-up examinations, only in the study group.
In our study, split bolus CTU allowed a radiation dose reduction of $37 \%$. According to the protocol employed, the reported radiation dose exposure for standard CTU examinations ranges from 20 to $66 \mathrm{mSv}$, [26] compared with a mean effective dose (ED) of 5-10 mSv for intravenous urography [27]. This represents the biggest concern tampering the use of CTU in the daily clinical practice, particularly in young patients (i.e., stones, infections) or for follow-up purposes (i.e., complex renal cysts, treated carcinomas). For these reasons several techniques are currently used to reduce the radiation dose exposure in CT scans. Radiation dose mainly depends on the number of phases acquired, the scanning parameters employed and patient size. As a first approach, radiation dose exposure reduction must be obtained with the lowest number of phases as possible [7]. Another common approach is to lower the tube voltage, mainly employing the Attenuation-based Automated Tube Voltage Selection. This is nowadays provided as a software tool in CT scanners: the iodine attenuation increases as tube voltage is reduced, resulting in higher contrast enhancement [28], and 
leading both to radiation dose and CM reduction. This was shown in previous vascular studies performed at 90 and $100 \mathrm{kV}[29,30]$. Our CTUs were performed using a standard $120 \mathrm{kV}$ setting; therefore, being a retrospective study, it was not possible to attempt any effective reduction in $\mathrm{CM}$ dose injected. However, this remains an interesting research goal and a potential concern in patients with renal function impairment, as often those undergoing CTU. Another strategy to decrease radiation dose is to employ iterative reconstruction techniques and/or dual-energy CT, both not available in the employed scanner.

Our study has some limitations, related to its retrospective nature and the small and inhomogeneous study population (clinical indication, phases acquired). There are also some limits to consider while approaching split-bolus CTU protocols (as also standard CTU studies). The arterial phase is not routinely performed; therefore, the protocol may be suboptimal for an accurate staging of tumours occasionally detected and such patients may require additional contrast-enhanced studies (i.e., MRI). The proper timing of double CM bolus is essential to avoid partial/inhomogeneous opacification of the urinary tract; the reduced amount of the first CM bolus may lead to lower HU values of iodinated urine as compared to a standard CTU. However, the final evaluation generally relies on the overall opacification by a qualitative point of view, and this seems to be similar between the two techniques, as reported in our study.

\section{Conclusion}

Split bolus CTU demonstrated to combine proper urinary opacification and diagnostic capability, allowing a concomitant significant reduction of radiation dose (about 37\%). This may allow an implementation of this feasible technique in the daily clinical practice for patients with diseases affecting the urinary tract.

\section{Acknowledgements}

This work was supported in statistical processing by Francesca Pregnolato.

\section{Conflict of Interest}

The authors declare no conflict of interest.

\section{Bibliography}

1. Potenta SE., et al. "CT Urography for evaluation of the Ureter". RadioGraphics 35 (2015): 709-726.
2. Van der Molen AJ., et al. "CT urography: definition, indications and techniques. A guideline for clinical practice". European $R a-$ diology 18 (2008): 4-17.

3. Silverman SG., et al. "What is the current role of CT urography and MR urography in the evaluation of the urinary tract?". $R a$ diology 250 (2009): 309-323.

4. Sung MK., et al. "Current status of low dose multi-detector CT in the urinary tract”. World Journal of Radiology 3 (2011): 256265.

5. Poletti PA., et al. "Low-dose versus standard-dose CT protocol in patients with clinically suspected renal colic." AJR American Journal of Roentgenology 188 (2007): 927-933.

6. Geyer LL., et al. "State of the art: iterative CT reconstruction techniques". Radiology 276 (2015): 339-357.

7. World Health Organization. "Basics of radiation protection for everyday use. How to achieve ALARA: working tips and guidelines". World Health Organization, Geneva.

8. Scialpi M. et al, "Split-Bolus Single-Pass Multidetector-Row CT Protocol for Diagnosis of Acute Pulmonary Embolism”. Iranian Journal of Radiology 13 (2016): e19844.

9. Chai RY., et al. "Comprehensive evaluation of patients with haematuria on multi-slice computed tomography scanner: protocol design and preliminary observations". Australas Radiology 45 (2001): 536-538.

10. Scialpi M., et al. "Split bolus multi detector-row computed tomography technique for characterization of focal liver lesions in oncologic patients". Iranian Journal of Radiology 13 (2016): e20143.

11. Brook OR., et al." Split-bolus spectral multi detector CT of the pancreas: assessment of radiation dose and tumor conspicuity". Radiology 269 (2013): 139-148.

12. American College of Radiology ACR Appropriateness Criteria ${ }^{\circledR}$ (Revised 2018) Acute pyelonephritis.

13. McColloug CH., et al. "CT dose reduction and dose management tools: overview of available options". RadioGraphics 26 (2006): 503-512.

14. Lescay HA., et al. "Anatomy, Abdomen and Pelvis, Ureter". Stat Pearls Publishing. 
15. Landis JR., et al. "The measurement of observer agreement for categorical data". Biometrics 33 (1977): 159-174.

16. Sheth S., et al. "Current concepts in the diagnosis and management of renal cell carcinoma: role of multidetector ct and three-dimensional CT". Radiographics 21 (2001): S237-S254.

17. Wang L.J., et al. "Diagnosis of acute flank pain caused by ureteral stones: value of combined direct and indirect signs on IVU and unenhanced helical CT". European Radiology 14 (2004): 1634-1640.

18. Karlo CA., et al. "Split-bolus dual-energy CT urography: protocol optimization and diagnostic performance for the detection of urinary stones". Abdom Imaging 38 (2013): 1136-1143.

19. Kekelidze M., et al. "Kidney and urinary tract imaging: triplebolus multidetector CT urography as a one-stop shop - protocol design, opacification, and image quality analysis". Radiology 255 (2010): 508-516.

20. Chow L., et al. "Split-Bolus MDCT Urography with Synchronous Nephrographic and Excretory Phase Enhancement". AJR American Journal of Roentgenology 189 (2007): 314-322.

21. Martignano P., et al. "64-Slice CT urography: 30 months of clinical experience”. Radiologia Medica 115 (2010): 920-935.

22. Cohan RH., et al. "MDCT urography: exploring a new paradigm for imaging of bladder cancer". AJR American Journal of Roentgenology 192 (2009): 1501-1508.

23. Babjuk M., et al. "EAU guidelines on non-muscle-invasive urothelial carcinoma of the bladder: update 2016". European Urology 71 (2017): 447-461.

24. Lee D., et al. "Optimization of split-bolus CT urography: effect of differences in allocation of contrast medium and prolongation of imaging delay". AJR American Journal of Roentgenology 209 (2017): W10-W17.

25. Chen CY., et al. "Diagnostic performance of split-bolus portal venous phase dual-energy CT urography in patients with hematuria". AJR American Journal of Roentgenology 206 (2016): 1013-1022.

26. Van der Molen A.J., et al. "A survey of radiation doses in CT urography before and after implementation of iterative recon- struction". AJR American Journal of Roentgenology 205 (2015): 572-577.

27. Jinzaki M., et al. "Role of computed tomography urography in the clinical evaluation of upper tract urothelial carcinoma". International Journal of Urology 23 (2016): 284-298.

28. Seyal AR., et al. "CT of the Abdomen with Reduced Tube Voltage in Adults: A Practical Approach". RadioGraphics 35 (2015): 1922-1939.

29. Nakayama Y., et al. "Lower tube voltage reduces contrast material and radiation doses on 16-MDCT aortography". AJR American Journal of Roentgenology 187 (2006): W490-W497.

30. Ippolito D., et al. "Low $\mathrm{kV}$ settings CT angiography (CTA) with low dose contrast medium volume protocol in the assessment of thoracic and abdominal aorta disease: a feasibility study". British Journal of Radiology 88 (2015): 20140140.

\section{Assets from publication with us}

- Prompt Acknowledgement after receiving the article

- Thorough Double blinded peer review

- Rapid Publication

- Issue of Publication Certificate

- High visibility of your Published work

Website: www.actascientific.com/

Submit Article: www.actascientific.com/submission.php

Emaill us: editor@actascientific.com

Contact us: +919182824667 